\title{
LICHTENBERG: UM RADIODRAMA DE WALTER BENJAMIN TRANSFORMADO EM FILME
}

\author{
Lichtenberg: a Walter Benjamin's radio drama turned into a film \\ Lichtenberg: un radiodrama de Walter Benjamin transformado en película
}

\author{
José Wenceslau Caminha Aguiar Junior \\ Professor na Escola Guignard/UEMG \\ laucaminha@yahoo.com
}

\section{Resumo}

Este texto objetiva descrever o processo criativo de adaptação do radiodrama Lichtenberg: um corte transversal, trabalho semificcional de Walter Benjamin sobre um professor alemão do século XVIII, para a linguagem cinematográfica, que resultou no curta-metragem Lichtenberg. O método utilizado é o estudo de caso, cujo objeto é o referido curta, que mostra a vida do personagem observada por um grupo de habitantes da Lua. Sigmund Freud, Angela Materno e Walter Benjamin são alguns dos autores que fundamentam o artigo. Nele são apresentadas as referências visuais utilizadas no desenho de produção do curta-metragem, com ênfase nas referências cinematográficas, assim como os aspectos conceituais e práticos da criação dos personagens, cenários e figurinos. O resultado é o entendimento da realização do filme, que poderá contribuir para futuras produções audiovisuais.

Palavras-chave: Animação. Walter Benjamin. Georg Christoph Lichtenberg.

\begin{abstract}
This text aims to describe the creative process of adapting of the radio drama Lichtenberg: $a$ cross-sectional, a semi-sectional work by Walter Benjamin about an 18th century German teacher, for film language, which resulted in the short film Lichtenberg. The method used is the case study, whose object is the referred short, which shows the life of the character observed by a group of inhabitants of the Moon. Sigmund Freud, Angela Materno and Walter Benjamin are some of the authors who support the article. It presents the visual references used in the short film production design, with emphasis on the cinematographic references, as well as the conceptual and practical aspects of the creation of the characters, sets and costumes. The result is an understanding of the making of the film, which may contribute to future audiovisual productions.
\end{abstract}

Key words: Animation. Walter Benjamin. Georg Christoph Lichtenberg.

\section{Resumen}

Este texto tiene como objetivo describir el proceso creativo de adaptación del radiodrama Lichtenberg: una seccion transversal, un trabajo semi ficticio de Walter Benjamin sobre un profesor de alemán del siglo XVIII, para el lenguaje cinematográfico, que resultó en el cortometraje Lichtenberg. El método utilizado es el estudio de caso, cuyo objeto es el referido corto, que muestra la vida del personaje observado por un grupo de habitantes de la 
Luna. Sigmund Freud, Angela Materno y Walter Benjamin son algunos de los autores que corroboran el artículo. En el se presentan las referencias visuales utilizadas en el diseño de producción del cortometraje, con énfasis en las referencias cinematográficas, así como los aspectos conceptuales y prácticos de la creación de los personajes, escenarios y disfraces. El resultado es una comprensión de la realización de la película, que puede contribuir a futuras producciones audiovisuales.

Palabras clave: Animación. Walter Benjamin. Georg Christoph Lichtenberg.

\section{INTRODUÇÃO}

Em seu livro $O$ mal-estar na civilização, Sigmund Freud propõe uma interessante metáfora sobre a memória humana, através da qual projeta o que, para ele, seria a sua forma ideal: aquela cujo coeficiente de acesso fosse total e onde os registros mnésicos acumulados pudessem ser desvelados seguidamente. Como um arqueólogo da psique humana, o pai da psicanálise usou como modelo a cidade de Roma, com seus períodos históricos inscritos nos diferentes estratos arquitetônicos e que - idealmente - se materializariam diante do olhar do observador:

[...] Isso significaria que, em Roma, os palácios dos césares e as Septizonium de Sétimo Severo ainda se estariam erguendo em sua antiga altura sobre o Palatino e que o castelo de Santo Ângelo ainda apresentaria em suas ameias as belas estátuas que o adornavam até a época do cerco pelos godos, e assim por diante. [...] E talvez o observador tivesse apenas de mudar a direção do olhar ou a sua posição para invocar uma visão ou outra. [...] Nossa tentativa [...] mostra quão longe estamos de dominar as características da vida mental através de sua representação em termos pictóricos (FREUD, 1972, p. 77-79).

Procuro aqui realizar uma abordagem semelhante, ao descrever o processo criativo que fiz para a linguagem cinematográfica do radiodrama Lichtenberg: um corte transversal, ${ }^{1}$ escrito pelo filósofo alemão Walter Benjamim, cujo resultado é um curta-metragem em animação stop motion, exibido pela primeira vez na cidade brasileira de Belo Horizonte no dia 22 de março de $2014^{2}$.

Sua produção teve início como um projeto acadêmico de Pós-Doutorado junto ao CNPq, sob a supervisão do professor Heitor Capuzzo e foi finalizada com o patrocínio da lei Municipal de Incentivo à Cultura da Prefeitura de Belo Horizonte ${ }^{3}$. A tradução do original alemão, até então inédita no Brasil, foi realizada por Daniel Tadeu Esteves Santos, com

\footnotetext{
${ }^{1}$ Ao criar o título do curta-metragem, optei por retirar o subtítulo original "um corte transversal".

${ }^{2}$ No final do texto encontra-se a ficha técnica da produção do filme, no Anexo A.

${ }^{3}$ Projeto $n^{\circ}$ 798/FPC/2011.
} 
revisão do professor-leitor Georg Wink da Faculdade de Letras da Universidade Federal de Minas Gerais (UFMG). A editora alemã Suhrkamp cedeu gratuitamente os direitos do radiodrama para a adaptação para o cinema.

A relevância do filme reside no fato de que se trata de uma proposta inédita, que transformou uma obra radiofônica ficcional benjaminiana em um produto audiovisual. $\mathrm{O}$ fato de o filme ser em preto em branco, sem aspectos cômicos e que não busca atrair o público pela emoção, faz dele um filme diferenciado, por não possuir os apelos típicos da indústria cultural.

\section{A TRANSFORMAÇÃO DO RADIODRAMA LICHTENBERG PARA A LINGUAGEM CINEMATOGRÁFICA}

Lichtenberg é um texto que usa a ficção científica para descrever a vida do personagem homônimo e se baseia em vários eventos de fato acontecidos: seu núcleo narrativo é um grupo de seres que, da Lua, observam as atribulações desse professor que viveu em Göettingen, uma cidade alemã, no século XVIII. Uma primeira camada surge aqui: o entorno/recorte histórico que envolve a escrita deste radiodrama. O ano era 1933: naquele momento Benjamin observava a chegada de uma grande mudança no horizonte político da Alemanha: Hitler havia sido nomeado chanceler e os desdobramentos do incêndio do Reichstag acabaram por conferir ao líder nazista poderes ditatoriais para levar adiante a sua política antissemita e anticomunista. Para Benjamim, judeu e marxista, só restava partir para o exílio.

Talvez um dos motivos do personagem histórico Georg Christoph Lichtenberg ter chamado a atenção de Benjamin tenha sido a sua deformidade física: a corcunda. $\mathrm{O}$ autor mantinha desde a infância uma relação próxima com a figura do corcundinha, personagem de uma história infantil alemã que o fascinava e que ele, em Infância em Berlim, identifica com certo senhor "sem jeito". Em uma brincadeira, habitual entre os alemães, sua mãe costumava dizer que o senhor "sem jeito" lhe "mandara lembranças", sempre que, menino, ele quebrava alguma coisa (BENJAMIN, 1987, p. 141 apud MURICY, 1998, p. 11) ${ }^{4}$. A má-formação da coluna influenciou na maneira um tanto derrisória como Lichtenberg via o mundo. Ainda assim, ele não deixava de ter um senso de humor sobre sua condição: "Minha cabeça", ele explicou, "está pelo menos 30 centímetros mais perto do meu coração do que a dos outros homens: é por isso que eu sou tão razoável" (KIMBALL, 2002).

\footnotetext{
${ }^{4}$ BENJAMIN, Walter. Infância em Berlim. In: p.141.
}

Obras escolhidas II, São Paulo: Brasiliense, 1987, 
Benjamin se valeu de uma pesquisa sobre o professor realizada sob a encomenda de um colecionador e à qual se dedicou por dois anos (1930/31) como a fonte histórica para produzir seu radiodrama. Escrever essa obra semificcional pode ter sido para Benjamin um recurso para se colocar mentalmente longe da Terra - pois metade da narrativa se passa na Lua - e se afastar, ainda que através da imaginação, das agruras e temores terrenos que o afligiam e que se materializaram sete anos depois, levando à sua morte em circunstâncias violentas ${ }^{5}$. O risco de morte, que cada vez se tornava mais palpável vai, no radiodrama, se metamorfosear em personagens livres do fardo da mortalidade: os lunares. Em sua última carta escrita antes de partir da Alemanha, um dia após o incêndio do Reichstag, ele escreveu ao seu amigo Gershom Scholem:

Quando consigo me desligar do fascinante universo de Lichtenberg, preocupa-me o problema que os próximos meses representam para mim, sem saber como irei sobreviver dentro ou fora da Alemanha. Há lugares onde eu poderia ganhar uma quantia mínima e outros onde poderia viver desse mínimo, mas não existe um só lugar que reúna as duas condições (BENJAMIN, 1993, p.45 apud MATERNO, 1998, p.35) ${ }^{6}$.

Ao tratar dos exílios e deslocamentos gerados pelo ambiente conturbado da primeira metade do século XX - do qual Benjamin, infelizmente, é um exemplo notável - George Steiner afirma:

No barbarismo do século 20, os artistas, escritores e intelectuais foram frequentemente caçados, transformando-se em exilados e refugiados, expulsos de sua língua, das comunidades de reconhecimento em que suas criações poderiam se ter desdobrado. Foram forçados a produzir textos curtos e esópicos sob a pressão da necessidade material e da censura (2001).

Para Benjamin, a escrita de radiodramas e a atuação como locutor de rádio foram expedientes valiosos utilizados para completar seu orçamento, face às suas dificuldades financeiras. ${ }^{7}$ Lichtenberg, seu último radiodrama escrito antes da partida para o exílio, nunca chegou a ser transmitido pelas ondas do rádio na Alemanha da época. O rádio, juntamente com o cinema, era o grande veículo de comunicação de massa do período e sua potência ficou clara quando, na noite de 30 de outubro de 1938, Orson Welles e seu programa Mercury

\footnotetext{
${ }^{5}$ Durante sua tentativa de fuga para os Estados Unidos, Benjamim foi retido em Portbou, Espanha. Por acreditar que seria entregue aos nazistas, cometeu suicídio em 26 de setembro de 1940.

${ }^{6}$ BENJAMIN, W. Correspondance II. Paris: Aubier, p. 78. BENJAMIN, W; SCHOLEM, G. Correspondência: 1933-1940. São Paulo: Perspectiva, 1993, p. 45.

${ }^{7}$ Entre 1927 e 1932, emissoras de rádio de Berlim e Frankfurt transmitiram 84 programas escritos por Benjamin, em alguns dos quais ele também atuou como locutor (MATERNO, 1998, p. 36).
} 
theater on the air levou o pânico a milhares de residências da região nordeste dos Estados Unidos com a sua versão radiofônica de Guerra dos mundos, de H.G. Wells.

Georg Christoph Lichtenberg (1742-1799) que, no radiodrama, é o humano que se torna objeto de estudo dos lunares, foi professor da Universidade de Göttingen, na Baixa Saxônia, onde lecionou física, química, geologia, meteorologia e astronomia entre 1769 e 1799. Admirado por Schopenhauer, que o designava "mestre do aforismo e do ensaio", formas de literatura então reservadas aos franceses: esse filósofo guardou seu maior elogio para Lichtenberg, declarando que ele era um Selbstdenker, alguém que genuinamente pensava por si mesmo (KIMBALL, 2002).

Nietzsche considerava o livro de Lichtenberg Aforismos (Sudelbücher) "um dos poucos livros alemães dignos de admiração" (MENDES, 1994, p. 1206). Por declarações como: "Se as pessoas quisessem narrar sinceramente seus sonhos, aí então o caráter do homem poderia ser interpretado melhor do que por sua cara" ${ }^{8}$ (ZITATE) Lichtenberg foi reconhecido por Freud como um precursor da psicanálise. Ele transitou pela filosofia e foi amigo de luminares do seu tempo, como Goethe e Kant.

Lichtenberg também produziu uma literatura inacabada, com títulos como $O$ príncipe duplo, A Ilha Cebu, Kunkel, O Parakletor. Sua única produção textual publicada ainda em vida foi a colaboração para o Almanaque de bolso de Göttingen, que aconteceu entre 1777 e 1799, onde ele escreveu sobre assuntos dos mais variados: História natural das moscas domésticas e Sobre a guilhotina, entre outros. Visitou a Inglaterra duas vezes: a primeira em 1770 e, na segunda, entre agosto de 1774 e dezembro de 1775. Lichtenberg realizou pesquisas sobre astronomia e eletricidade: estudou como as descargas elétricas se ramificam e formam imagens, criando as famosas figuras de Lichtenberg. Suas pesquisas lhe valeram a visita do também cientista Alessandro Volta em 1784, além de ter sido o primeiro a instalar na Europa o para-raios inventado por Benjamin Franklin.

No radiodrama, a escolha de Lichtenberg pelos lunares como espécime a ser analisada se dá pelo fato do mesmo ter finalizado um mapa lunar cuja elaboração havia sido iniciada por outro astrônomo, seu contemporâneo, Tobias Mayer. Aquele que observa a Lua se torna objeto de observação por parte dos habitantes lunares através do espectrofone, o principal aparelho usado para observar a Terra.

\footnotetext{
8 "Wenn Leute ihre Träume aufrichtig erzählen wollten, da ließe sich der Charakter eher daraus erraten als aus dem Gesicht."
} 
Esse aparelho, descrito por Benjamin, ainda que se assemelhe a um telescópio, na verdade atua como um microscópio: a espécie humana é escrutinada como uma amostra em uma lâmina de vidro, pois os lunares nos veem como seres limitados dentre as espécies da fauna cósmica - somos mortais, conscientes da nossa finitude e por ela perpassados - e eles são eternos; nossa existência é marcada por dissabores e tristezas, e eles vivem em um estado de permanente alegria suave. Somos seus antípodas... Como afirma o personagem lunar Labu:

"As amostras casuais dos últimos milênios ainda não nos permitem dizer se o ser humano seria capaz de evoluir. Ao partirmos do ponto de que isso é um fato científico seguramente embasado, nas nossas reuniões de agora em diante tratar-se-á simplesmente de provar a hipótese de que ele é fruto da infeliz condição humana, mas a causa dessa infelicidade divide as opiniões" (BENJAMIN, 1972, p. 697-698).

Os lunares não querem investigar se o ser humano é infeliz: isto para eles é um fato consumado. Eles querem entender como a infelicidade nos afeta. A vida do personagem principal, perpassada por dissabores e frustrações é, a meu ver, absolutamente atual e torna ainda mais relevante a abordagem benjaminiana: embora tenhamos avançado em muitos aspectos na nossa caminhada civilizatória, em termos emocionais o ser humano pouco mudou em relação àqueles que viveram no século XVIII. A vida atribulada e sofrida do personagem ecoava, à época da sua escrita, a situação do próprio Benjamin. Segundo Angela Materno:

Lichtenberg forneceu mais do que uma atraente silhueta ou um interessante personagem para um radiodrama. Forneceu também, para Walter Benjamin, traços para o desenho de um autorretrato em terceira pessoa. [...] Benjamim fala por meio de um pensador e escritor do século XVIII que não se fixou em nenhum sistema estabelecido de pensamento ou de escrita, de sua própria situação de intelectual, no século XX, à margem das instituições e dos gêneros literários e filosóficos consagrados (1998, p. 39).

O próprio Lichtenberg era um observador da espécie humana: "A função principal da minha vida', ele anotou em seu diário em 1771, 'é observar os rostos das pessoas'. Um comentarista o descreveu como um "espião na humanidade". Era quase literalmente verdade. Lichtenberg ficava encantado em observar as cenas de rua com um telescópio do alto de sua janela" (KIMBALL, 2002).

Para mim, o radiodrama Lichtenberg acenou como um atraente argumento para a realização de um filme: por ter sido escrito para o rádio, calcado na interpretação vocal e na 
sonoplastia, foi possível uma grande liberdade criativa no que tange ao aspecto visual, definido pelo desenho de produção.

A opção de Benjamin: lançar mão da ficção científica para tratar da personalidade múltipla de um personagem que realmente existiu e, na qual, olhares alienígenas tentam entender a trajetória de um humano, o levou a criar um terreno no qual essas duas camadas narrativas continuamente se sobrepõem e se mesclam. Segundo Materno, o radiodrama “[...] não delineia uma silhueta contínua, fechada e conclusiva de Lichtenberg, mas que atravessa seus escritos, relatos, incertezas e contradições, de modo a justapor os vários rostos, momentos e lugares de suas experiências e reflexões" (1998, p. 38).

Esse procedimento em muito se assemelha à forma como, oito anos depois, Herman Mankiewicz e Orson Welles criaram o roteiro de Citizen Kane (Cidadão Kane, 1941), pois o personagem principal é também um personagem multifacetado e construído através de depoimentos fragmentados daqueles que compunham o seu círculo mais íntimo. Essa semelhança se torna ainda mais clara através dos personagens que acompanham o enterro de Lichtenberg e que, como em Kane, emitem suas opiniões sobre alguém que morrera recentemente. A própria introdução do radiodrama, realizada através de um narrador, se assemelha ao jornal da tela News on the march de Kane, pois, através dela, nos são fornecidas as primeiras pinceladas sobre a história que nos será narrada.

O ambiente tecnológico criado por Benjamin - outra camada importante no contexto da narrativa - no qual os lunares estão inseridos e que permite que estes possam observar com relativa precisão os acontecimentos que ocorrem a mais de 350.000 quilômetros de distância, é reflexo do zeitgeist tecnológico que perpassava as primeiras décadas do século XX, após o fim da Primeira Guerra Mundial: as pesquisas com fins bélicos, desenvolvidas durante o conflito e os avanços técnicos delas decorrentes, apontavam para um futuro de possibilidades ilimitadas, traduzido, por exemplo, nas feiras mundiais, como a realizada em Chicago no mesmo ano em que Benjamin escreveu Lichtenberg, e cujo título era 1833-1933 - Um século de progresso. Para Materno:

O Comitê Lunar, misturado às suas aparelhagens e delas dependentes, cita, portanto, de certo modo, o próprio rádio e seu contexto cultural (que também é o de Benjamin): o contexto das invenções e inovações técnicas do século XX, da popularização da fotografia, das emissões radiofônicas, do cinema, da ampliação da indústria bélica, da propaganda etc. (1998, p. 42). 
Em relação às referências cinematográficas do curta-metragem Lichtenberg as principais são os filmes Le voyage dans la Lune (Viagem à Lua), de Georges Méliès (1902), cujos cenários eram compostos por imagens bidimensionais dispostas em relevo para sugerir a profundidade da cena, First men in the Moon (Os primeiros homens na Lua, 1964) de Nathan Juran, cujos efeitos de stop motion foram criados pelo mestre Ray Harryhausen, com sua belíssima direção de arte e cenários lunares bastante convincentes e The adventures of Baron Munchausen (As aventuras do Barão de Munchausen, 1988) de Terry Gilliam, nos quais parte significativa das sequências se passa na Lua. Neste último, o diretor e o desenhista de produção lançaram mão das possibilidades visuais que o jogo entre a planaridade e a tridimensionalidade pode oferecer, além do uso de enquadramentos para criar curiosas relações de escala.

A animação presta uma homenagem a esses diretores e/ou animadores que criaram clássicos da cinematografia mundial que povoam o imaginário de milhões de pessoas e são referências para incontáveis animadores de várias gerações: Georges Méliès, por ter sido o primeiro diretor a transformar o cinematógrafo em um dispositivo para criar narrativas ficcionais e mergulhar o espectador no universo onírico que o cinema propicia; Ray Harryhausen, cujo trabalho com stop motion nos filmes como, por exemplo, The 7th voyage of Sinbad (Simbad e a princesa, Nathan Juran, 1958), It came from beneath the sea (O monstro do mar revolto, Robert Gordon, 1955) e Earth vs. the flying saucers (A invasão dos discos voadores, Fred F. Sears, 1956). E também a Terry Gilliam, diretor que, em várias ocasiões, teve que enfrentar inúmeros obstáculos para realizar seus filmes, como geralmente acontece com os diretores que buscam criar um cinema autoral.

Para servir como referência para o desenho de produção foi realizada uma pesquisa sobre filmes realizados no final da década de 1920 e início da década de 1930, a época em que Walter Benjamin escreveu seu radiodrama: Metropolis (Fritz Lang, 1927), Flash Gordon (Frederick Stephani, 1936) e Frankenstein (James Whale, 1931) entre outros e onde a presença de aparatos elétricos é um importante elemento cenográfico: assim, na animação, as máquinas utilizadas pelos personagens lunares têm como característica o uso da eletricidade. Objetos originalmente utilizados em sistemas elétricos foram transformados em máquinas lunares. Um exemplo é o parlamônio, aparelho “com o qual se pode transformar as maçantes conversas humanas em música para os habitantes lunares, entediados com a música das esferas" (BENJAMIN, 1972, p. 697), construído com isolantes de cerâmica para alta voltagem. Já no espectrofone a eletricidade é um elemento visual aparente: ele é flanqueado 
por duas escadas de Jacó (arcos voltaicos que ascendem através de duas hastes) (Figura 1), criadas pelo professor José Osvaldo Saldanha Paulino, da Escola de Engenharia da UFMG.

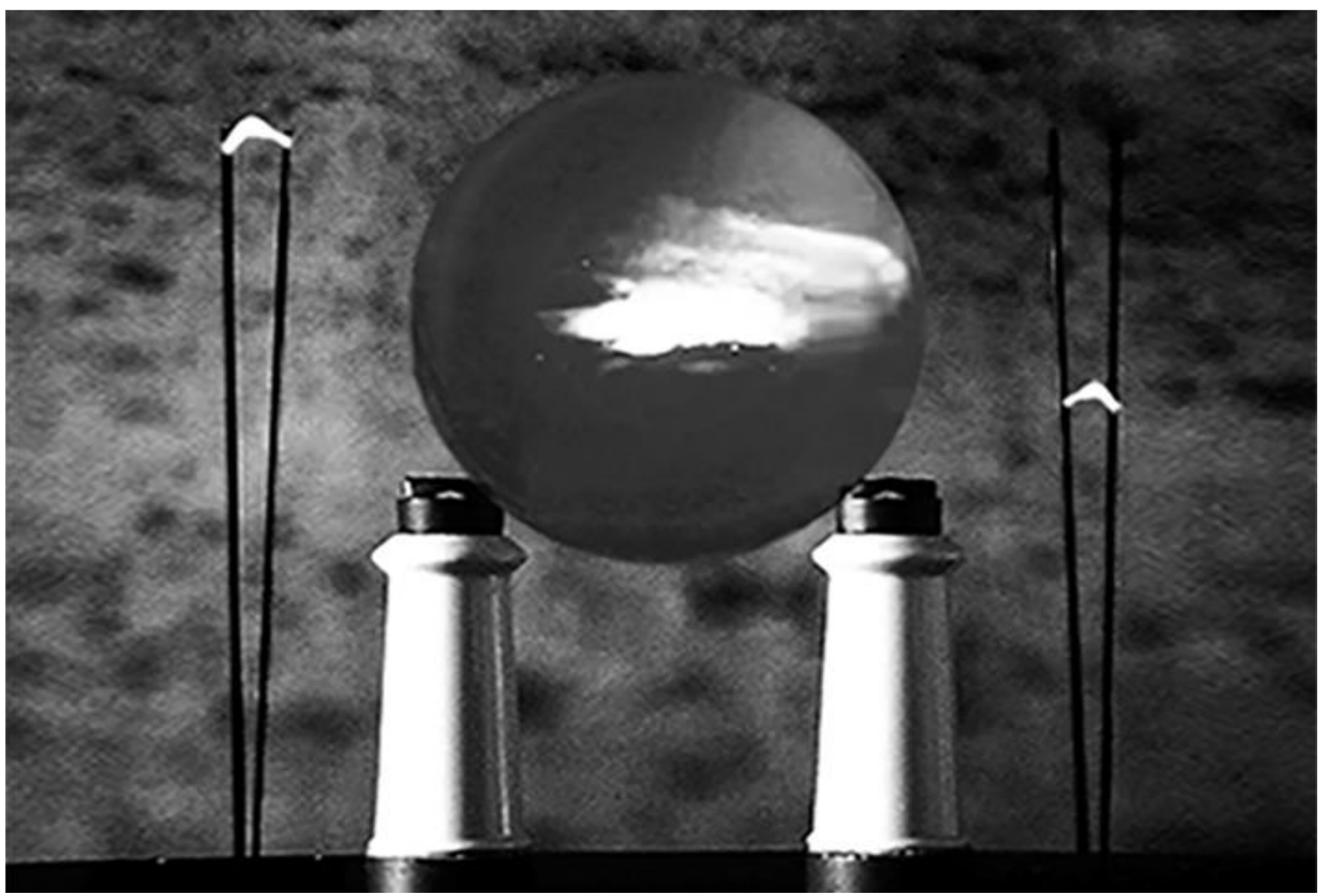

Figura 1 - Espectrofone

Fonte: imagem da produção do filme Lichtenberg

Todos os dispositivos utilizados pelos lunares remetem ao círculo ou à esfera, explicitando cenograficamente que a vida dos lunares é livre das arestas existenciais humanas. É possível que para criar o parlamônio Benjamin tenha se inspirado no Optophone, aparelho criado por Fournier d'Albe em 1913, descrito como dispositivo que "transformava a página impressa em som. A luz refletida pelas células de selênio da máquina produzia tons musicais correspondentes às letras digitadas em uma página" (HOW). Ao tratar do parlamônio e do espectrofone, no site Museum of imaginary musical instruments está a seguinte observação:

Com Lichtenberg, Benjamin percebeu a capacidade do rádio para conjurar instrumentos imaginários. Através dos efeitos sonoros dos anéis e zumbidos, o espectrofone adquire materialidade dentro do observatório lunar. Através da fusão do discurso para a música, o parlamonium retira seu efeito. E, implicitamente, a peça transforma o rádio em um espectrofone sem imagem, permitindo que o homem sintonize sons na lua ([2000]). 
No que concerne à cenografia, buscou-se estabelecer a maior proximidade possível entre os ambientes presentes na narrativa e seus correspondentes históricos: locais onde acontecem as sequências foram localizados na Internet e usados como referência para a criação das maquetes. Do teatro Drury Lane (Figura 2), por exemplo, ainda hoje existente em Londres, foi possível obter imagens da sua planta-baixa no século XVIII, vistas da plateia e do palco, existentes em gravuras e pinturas daquele período.

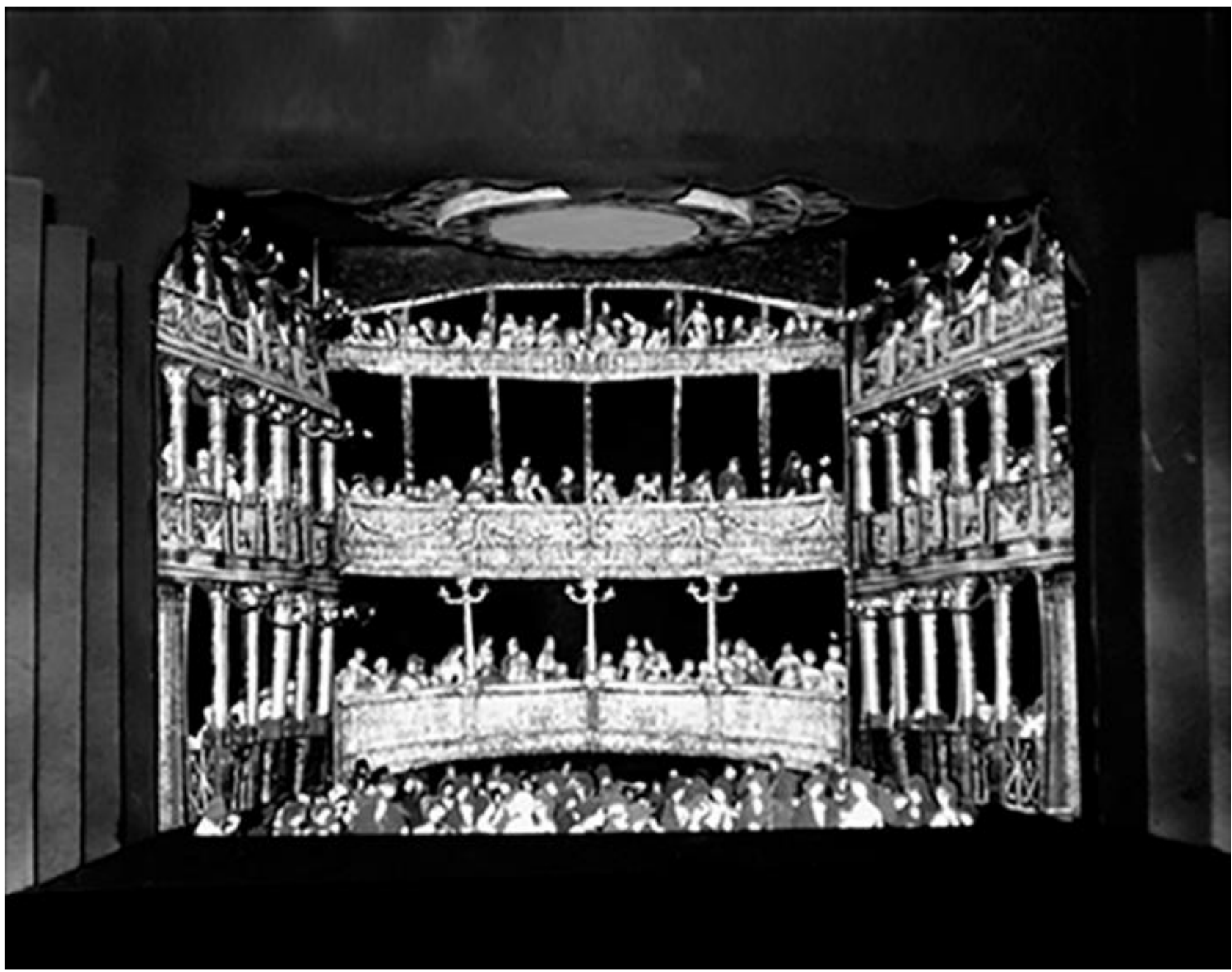

Figura 2 - Cenário do Teatro Drury Lane

Fonte: arquivo de produção do filme Lichtenberg

Já na criação da casa do personagem principal, foi usada como referência a residência da família Lichtenberg, onde o professor nasceu. Tanto para a criação dessas duas maquetes, quanto para várias cenas estáticas que estão inseridas no filme, foi utilizado o recurso da tridimensionalização de imagens originalmente bidimensionais, através de um software de manipulação de imagens: essas foram redimensionadas para a posição frontal e, através de anamorfoses, desmembradas em seções individuais, aplicadas sobre superfícies rígidas e 
montadas para criar uma cenografia volumétrica, semelhante aos cartões pop up, procedimento também aplicado às imagens da cidade de Göttingen.

Alguns dos personagens, como Lichtenberg (Figura 3) e o ator inglês David Garrick, por exemplo, tiveram suas feições originais reproduzidas nos pequenos rostos modelados para ser usados nas filmagens em stop motion.

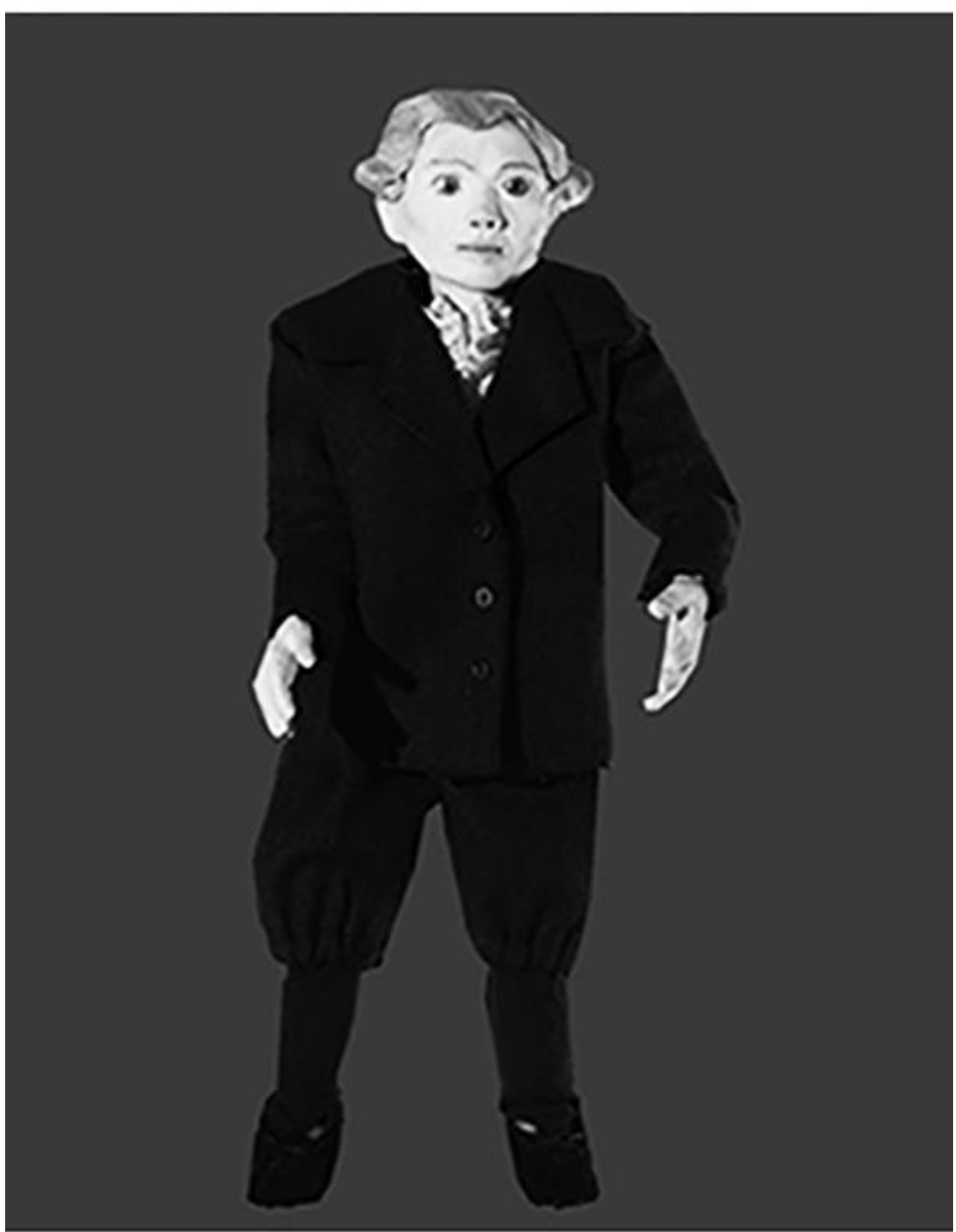

Figura 3 - Personagem Lichtenberg

Fonte: imagem da produção do filme Lichtenberg

Para os outros personagens foram criados rostos que reproduzem as feições de atores e diretores de cinema (John Huston, Roman Polanski e Jack Nicholson, entre outros) (Figura 4). 


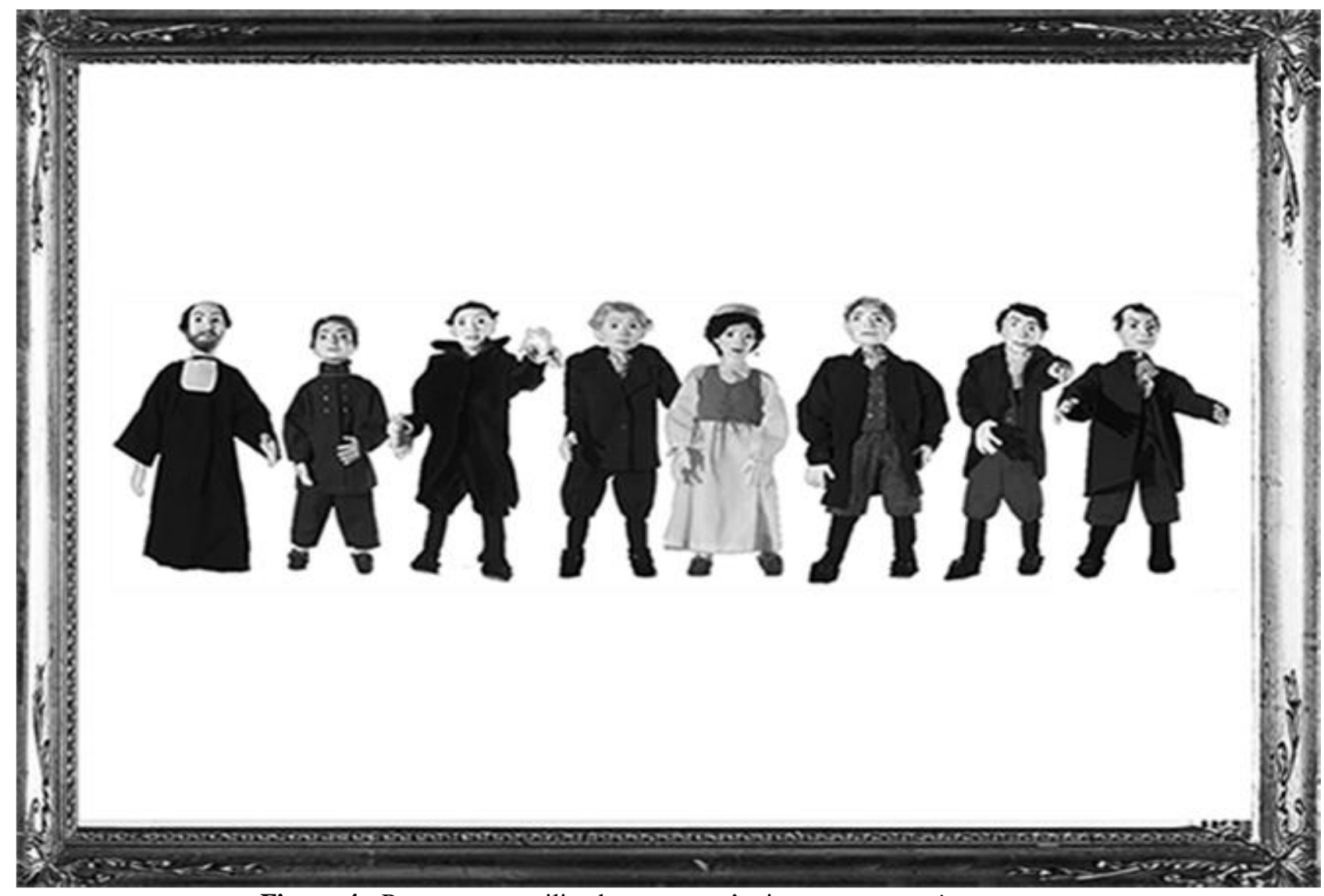

Figura 4 - Personagens utilizados nas sequências em stop motion

Fonte: imagem da produção do filme Lichtenberg

Os personagens eram compostos por um esqueleto metálico revestido de espuma e usavam figurinos criados a partir da pesquisa sobre o vestuário europeu do século XVIII.

Para a criação dos personagens lunares, optou-se por uma massa luminosa - semelhante a um cérebro pulsante - encerrada em uma redoma que flutua (Figura 5). 


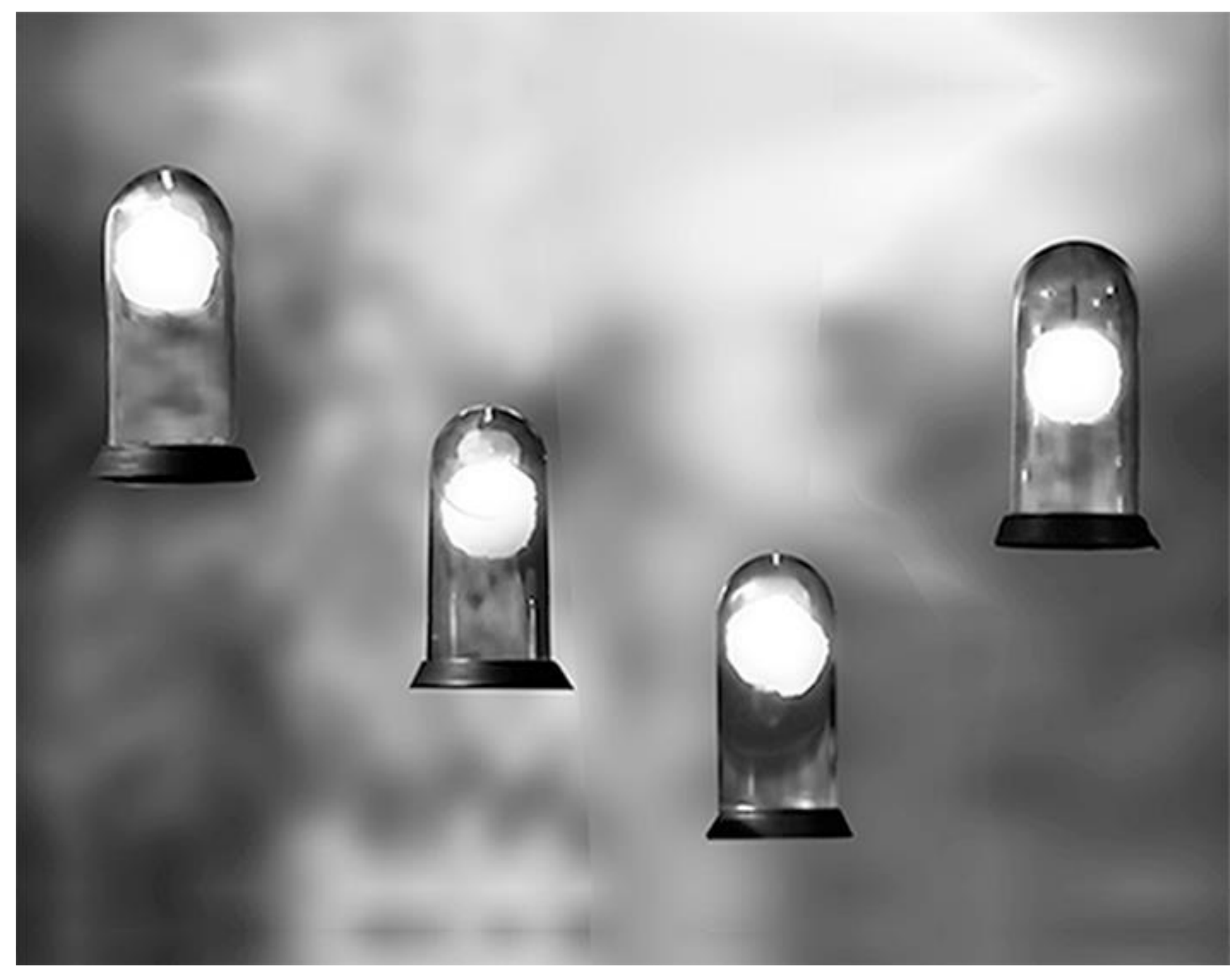

Figura 5 - Lunares

Fonte: fotograma do filme Lichtenberg

A cidade dos lunares foi criada a partir de uma imagem-conceito: uma vez que os habitantes da Lua são eternos, foi produzida uma cidade que fisicamente se assemelha a uma ampulheta deitada, na qual a areia não flui e, simbolicamente, o tempo permanece congelado. Ela surge no filme de dentro da cratera, onde normalmente permanece oculta aos olhares humanos (Figura 6). 


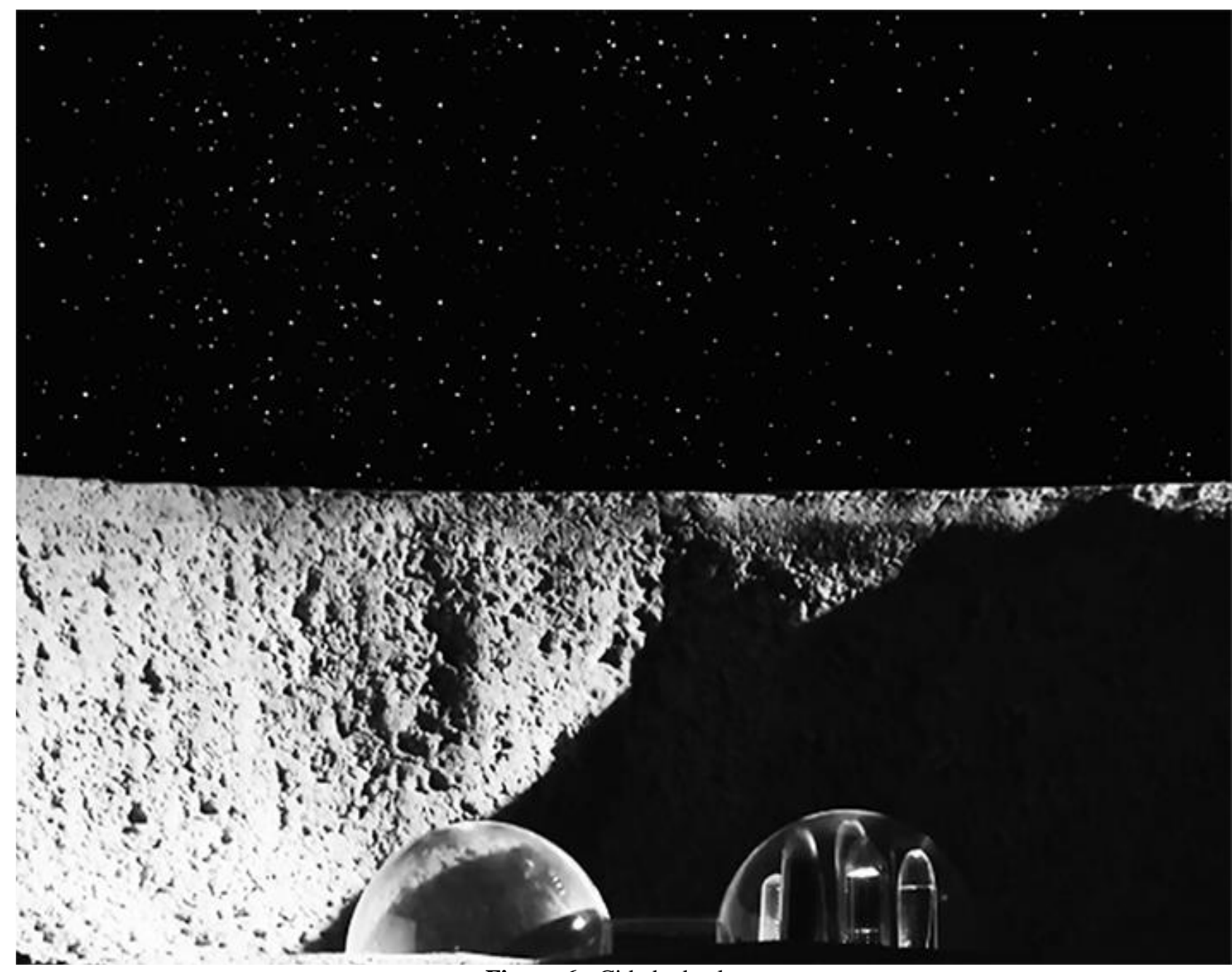

Figura 6 - Cidade dos lunares

Fonte: fotograma do filme Lichtenberg

A cratera onde os lunares vivem e realizam suas pesquisas teve sua curva de nível localizada na Internet ${ }^{9}$, o que permitiu reproduzi-la em duas escalas distintas, necessárias para tomadas específicas do filme. Quanto ao nome da cratera, Benjamin cria um jogo de espelhamentos: quando os lunares a batizam com o nome de Lichtenberg, do mesmo modo que os humanos o haviam feito, é instaurada uma narrativa ficcional sobre um evento de fato acontecido ou uma dupla nomeação: caso o ouvinte da narrativa resolva consultar o nome das crateras lunares, lá estará a própria...

\footnotetext{
${ }^{9}$ Imagem produzida pelo AMIE - Advanced Moon Imaging Experiment (Experimento Avançado Imagético da Lua, em uma tradução livre) a bordo da sonda SMART-1 da Agência Espacial Europeia. Ela se move ao redor da Lua e recebe comandos para focalizar um determinado_ponto da superfície durante um período, ainda que a nave se mova à velocidade de 3.260 quilômetros por hora. Ela registra imagens entre 2.064 e 2.162 quilômetros de distância, com a resolução entre 186 e 195 metros por pixel. A cratera Lichtenberg está localizada a $66.8^{\circ}$ Oeste e $32.6^{\circ}$ Norte (CRATER, 2006).
} 
Alguns dos cenários têm como referência mais de uma fonte, como é o caso do cenário no qual acontece a sequência em que Lichtenberg se encontra com Deus e este lhe entrega uma pequena esfera para que ele realize alguns experimentos. As referências foram duas: a imagem de um laboratório do século XVIII e imagens de armários de curiosidades, dos quais tratarei mais adiante. A criação dos diminutos aparelhos de vidro do laboratório ficou a cargo do professor Celso Pereira Fonseca da UFMG: ainda que diminutos, são de fato funcionais. Foram também construídos três armários em escala, onde foram colocados vários tipos de objetos em miniatura segundo uma taxonomia heterodoxa.

Muitas das cenas estáticas, que aparecem no espectrofone ou em flashs durante a narrativa, foram criadas agregando-se a imagem de Lichtenberg a cenas existentes em gravuras ou pinturas, como é o caso do personagem junto à família real inglesa, composta pelo rei George III, sua esposa Charlotte e seus seis filhos. Nesse sentido, o desenho de produção de Lichtenberg repete visualmente os procedimentos benjaminianos para a criação do radiodrama, ao mesclar camadas imagéticas que transitam entre o documental e o ficcional.

Segundo Materno: “[...] Aos ouvintes do radiodrama são oferecidos recortes, ou flashes de sua vida em situações, lugares e momentos diversos. Não há, portanto, neste radiodrama, construído de forma fragmentária e episódica, unidade de ação, tempo ou lugar” (1998, p. 43). Pode-se afirmar que a edição acontece à medida que um radiodrama se desenrola: as pausas, os efeitos sonoros, as diferentes entonações da leitura do roteiro pelos atores e atrizes, como a contraparte radiofônica da edição cinematográfica. Segundo Tim Crook, o radiodrama: “É auditivo na dimensão física, mas igualmente poderoso como força visual em sua dimensão psicológica". ${ }^{10}$ (CROOK, 1999, p. 8). Um exemplo é Orson Welles: quando chegou a Hollywood, trazia consigo uma vasta bagagem teatral, mas sua experiência radiofônica certamente foi de grande importância para torná-lo o extraordinário diretor de cinema que ele se tornou. Sua apurada noção de timing com certeza era oriunda da sua experiência no rádio. Welles fez uso da temporalidade como instrumento narrativo fundamental no roteiro de Citizen Kane (Cidadão Kane, Orson Welles, 1941), onde Mankiewics e Welles usaram da fragmentação temporal, das idas e vindas de espaços, tempos e ações para construir o famoso quebra-cabeça resolvido apenas pelo espectador e vetado aos personagens do filme.

10 "It is auditory in the physical dimension but equally powerful as a visual force in the psychological dimension". 
Na produção de Kane (Cidadão Kane, Orson Welles, 1941) foram construídas maquetes, composições visuais (colagens cinematográficas) e fusões criadas pelos técnicos em efeitos visuais, com resultados extremamente convincentes, que ajudaram a tornar o filme um dos mais importantes de todos os tempos. O interior da mansão do protagonista, o palácio Xanadu, por exemplo, foi criado com utilização de matte paintings (pinturas que mostram paisagens ou cenários, permitindo que se crie a ilusão de um ambiente que não está presente no local da filmagem). Impressões óticas foram utilizadas para, por exemplo, combinar filmagem ao vivo e miniaturas, ampliando as dimensões do teatro onde acontece a sequência da ópera. A animação stop motion foi também utilizada para movimentar os veículos na sequência da construção de Xanadu. Em seu ensaio Pictures, escrito em 1934, Gertrude Stein trata do desejo de se ter uma miniatura do mundo ao alcance dos nossos olhos e mãos:

[...] Sempre se gosta de coisas pequenas. Gosta-se dos modelos de peças de mobiliário, de pequenas jarras de flores, de pequenos jardins, de penny peep shows, de lanternas mágicas, de fotografias, de cinema, dos retrovisores dos automóveis porque eles reproduzem as imagens em pequeno e ainda por cima nas cores naturais como a objectiva de uma máquina fotográfica. Como eu já disse, gosta-se naturalmente das coisas em miniatura, é simples, tem-se tudo de uma vez... (STEIN apud MINK, 1996, p. 84).

Um exemplo de um espaço onde se mesclavam duas vontades: a de se encapsular o mundo dentro de um microcosmo privado e de fazer deste um local onde fantasias pudessem ser materializadas é o armário de curiosidades, uma derivação do chamado Wunderkammer, criado a partir do século XVI na Europa, cuja característica principal era a diversidade de objetos colecionados. Originalmente esse termo era usado para descrever os quartos e, posteriormente, a peça do mobiliário onde eram guardados animais empalhados ou conservados em álcool, esqueletos, minerais, obras de arte, material etnográfico e arqueológico e onde a fronteira que separava o fato da ficção era bastante nebulosa. Pierre Borel (1620-1671), um médico de Castres, possuía um gabinete no qual havia monstros de duas cabeças, fragmentos de múmias, anomalias animais, chifres de unicórnios, além de instrumentos científicos como lunetas, microscópios, globos terrestres e instrumentos astronômicos (RAFFAINI, 160).

No seu livro Viagem na irrealidade cotidiana, Umberto Eco comenta sua visita ao Museu Ripley, que ele considera uma “Wunderkammer por excelência” e onde: “[...] A autenticidade divulgada não é histórica, é visual ${ }^{11}$. Tudo parece verdadeiro, em todo caso é 
verdadeiro o fato de que pareça verdadeiro, e que a coisa com que pareça seja dada como verdadeira, ainda que, como Alice no País das Maravilhas, nunca tenha existido" (ECO, 1984, p. 23).

Acredito que o mesmo ocorria nos antigos Wunderkammer: se a presa do narval correspondia visualmente ao chifre do unicórnio, isso era suficiente para que ela fosse incorporada como tal... O próprio Lichtenberg colecionou "todo o tipo de memorabilia ao seu alcance" (MATERNO, 1998, p. 39), o que, no filme, levou à criação do cenário onde acontece o encontro de Lichtenberg com Deus: um local imaginário, flutuando acima da Terra, onde está presente uma amostra geral das coisas do mundo (Figura 7).

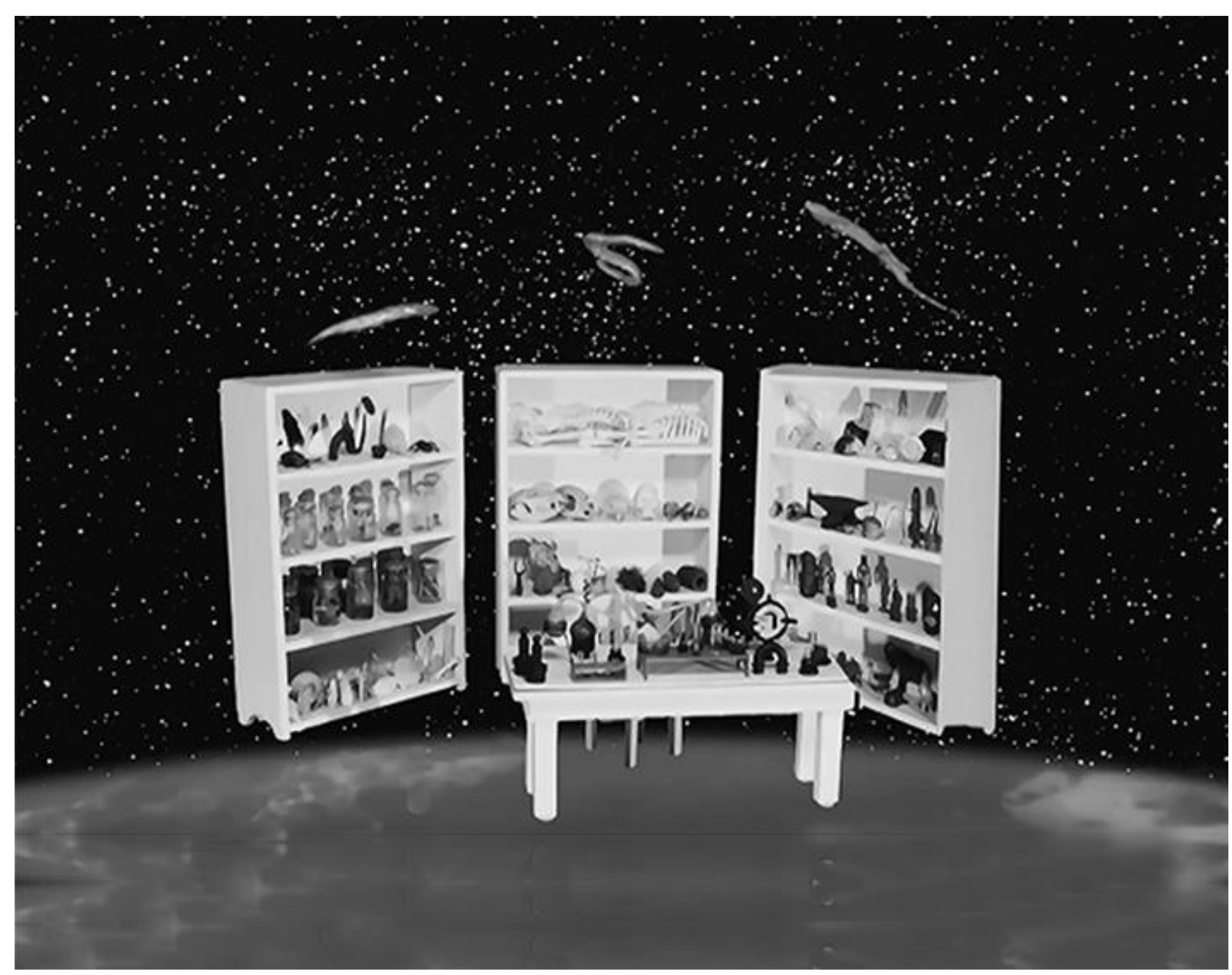

Figura 7 - Laboratório no espaço

Fonte: fotograma do filme Lichtenberg

Outra característica do curta-metragem Lichtenberg é a de ser um filme produzido desde o seu início em preto-e-branco: com exceção de apenas um objeto de cena, tudo o mais foi materializado em preto-e-branco. O motivo: no final dos anos 1920 e no início dos anos 1930, 
quando Benjamin escreveu Lichtenberg, a grande maioria dos filmes era realizada em preto-ebranco. Em segundo lugar, trata-se de uma escolha conceitual, cuja referência principal são as afirmações de Vilém Flusser sobre a fotografia p\&b:

O preto e o branco não existem no mundo, o que é uma grande pena. Caso existissem, se o mundo lá fora pudesse ser captado em preto-e-branco, tudo passaria a ser logicamente explicável. Tudo no mundo seria então ou preto ou branco, ou o intermediário entre os dois extremos. [...] As fotografias em preto-e-branco o provam, são cinzentas: imagens de teorias (óticas e outras) a respeito do mundo. [...] As fotografias em preto-e-branco são a magia do pensamento teórico, conceitual, e é precisamente nisto que reside o seu fascínio. Revelam a beleza do pensamento conceitual abstrato (FLUSSER, 2002 , p. 38 e 39 ).

O uso do preto-e-branco na animação Lichtenberg serve conceitualmente para descrever dois mundos antagônicos: o preto - a vida dos humanos, com sua mortalidade inelutável, seus sofrimentos, frustrações e incertezas, e o branco - os lunares e sua vida "suavemente alegre", livre do fardo da mortalidade e alicerçada em certezas absolutas.

A escolha pelas filmagens ao vivo para todas as sequências que se passam na Lua e pelo stop motion para as sequências terrestres também é uma opção conceitual: a filmagem ao vivo produziu uma fluidez de movimentos aos personagens lunares, enquanto o stop motion tem como característica um movimento levemente truncado. Isso, aliado ao fato de que os personagens humanos são construídos como pequenos bonecos reforça a ideia de que somos títeres manipulados pelo destino. Em termos visuais, o segmento de Lichtenberg em stop motion tem como referências principais os filmes The nightmare before christmas ( $O$ estranho mundo de Jack, 1993), produzido por Tim Burton, e Coraline e o mundo secreto, (2009), ambos dirigidos pelo diretor norte-americano Henry Selick.

$\mathrm{Na}$ iluminação do filme, buscou-se criar uma luz expressionista, mais dura, com sombras rasantes e o uso do chiaroscuro. Para a filmagem da sequência do teatro Drury Lane, a plateia foi iluminada por cerca de 60 pequenas velas, sendo as luzes da ribalta produzidas por dezoito minilamparinas a óleo. Essa opção por uma iluminação sem o uso de lâmpadas elétricas teve como referência o filme Barry Lyndon (1975), de Stanley Kubrick, cujas cenas de interior noturnas foram filmadas apenas com a iluminação de velas. Para tal, o diretor de fotografia John Alcott utilizou uma lente $50 \mathrm{~mm}$ desenvolvida para a NASA pela empresa Zeiss e que foi usada no programa Apollo (ROBEY, 2016).

Durante o processo de edição do filme, ficou clara para mim, como editor, a necessidade de reduzir o tempo da narrativa, dos originais 53 minutos, que respeitavam o 
texto original de Benjamin, para 29:51 minutos: a fruição se tornou mais satisfatória com o tempo de exibição encurtado, já que o timing narrativo dos anos 1930 em muito difere daquele dos anos 2000 .

\section{CONSIDERAÇÕES}

Este texto teve como escopo descrever o processo criativo de adaptação e transcrição do radiodrama Lichtenberg: um corte transversal, de Walter Benjamin, para a linguagem cinematográfica. O resultado é o entendimento da realização do filme, que poderá contribuir para futuras produções audiovisuais.

Embora, ao longo da narrativa, as mazelas e infelicidades do personagem Lichtenberg tenham sido sejam apresentadas: sua deformidade física, seus problemas econômicos, um ambiente acadêmico hostil e a perda súbita da mulher amada, ainda assim, no final Benjamin nos acena com alguma esperança, através da fala do lunar Labu:

\footnotetext{
"Assim, honradíssimos senhores, eu ouso pôr em dúvida o princípio de nossa pesquisa que diz que a infelicidade das pessoas não as faz evoluir. Talvez seja a infelicidade aquilo que as impulsiona - algumas delas, inclusive, tão longe quanto o professor Lichtenberg" (BENJAMIN, 1972, p.720).
}

Em um mundo cada vez mais caótico e conturbado, eivado de mentiras e discursos ilusórios de todo tipo e no qual as tristezas e amarguras nos atingem intermitentemente, talvez a visão de Benjamin nos traga um mínimo conforto existencial: a possibilidade de fazermos de nossas aflições o instrumento que nos impulsione durante nossa curta passagem por esse planeta, um grão de areia perdido na imensidão do Cosmo.

\section{REFERÊNCIAS}

BARRY Lyndon. Direção: Stanley Kubrick, Produção: Stanley Kubrick, GBR / EUA / Irlanda, 1975, colorido, 184 min., sonoro.

BENJAMIN, Walter. Lichtenberg: ein querschnitt. Gesammelte Schriften IV/ 1/2. Frankfurt am Main: Suhrkamp Verlag, 1972.

CITIZEN Kane (Cidadão Kane). Direção: Orson Welles, Produção: Orson Welles, USA, 1941, p\&b, 119 min., sonoro.

CORALINE (Coraline e o mundo secreto). Direção: Henry Selick, Produção: Claire Jennings, Bill Mechanic, Mary Sandell, Henry Selick, USA, 2009, p\&b, colorido, 100 min., sonoro. 
CRATER Lichtenberg and young lunar basalts tracked by SMART-1. European Space Agency (ESA). Smart-1. 02 mar. 2006. Disponível em: <http://www.esa.int/Our_Activities/Space Science/SMART1/Crater Lichtenberg and young lunar basalts tracked by SMART-1>. Acesso em: 21 jun. 2008.

CROOK, Tim. Radio drama: theory and practice. London; New York: Routledge, 1999, p. 8. Google books. Disponível em: <https://books.google.com.br/books?id=6AxqhT2f11YC\&pg=PA3\&hl=ptBR\&source $=$ gbs_toc_r\&cad $=4 \# \mathrm{v}=$ onepage $\& \mathrm{q} \& \mathrm{f}=\mathrm{false}>$. Acesso em: 07 set. 2019.

EARTH vs. the flying saucers (A invasão dos discos voadores). Direção: Fred F. Sears, Produção: Charles H. Schneer, USA, 1956, p\&b, 83 min., sonoro.

ECO, Umberto. Viagem na irrealidade cotidiana. Rio de Janeiro: Nova Fronteira, 1984.

FIRST men in the Moon (Os primeiros homens na Lua). Direção: Nathan Juran, Produção: Charles H. Schneer, GBR, 1964, colorido, 103 min., sonoro.

FLASH Gordon. Direção: Frederick Stephani, Produção: Henry MacRae, USA, 1936, p\&b, 245 min. (13 episódios), sonoro.

FLUSSER, Vilém. A filosofia da caixa preta: ensaios para uma futura filosofia da fotografia. Rio de Janeiro: Relume Dumará, 2002. (Conexões, 15)

FRANKENSTEIN. Direção: James Whale, Produção: Carl Laemmle Jr., USA, 1931, p\&b, 70 min., sonoro.

FREUD, Sigmund. O mal-estar na civilização. Edição standard brasileira das obras psicológicas completas de Sigmund Freud. Rio de Janeiro: Imago, 1972.

HOW we read: A Sensory History of Books for Blind People. Exhibition, Peltz Gallery, School of Arts, Birkbeck, London WC1H 0PD, 17-23 November 2014. Disponível em:

< http://www.howweread.co.uk/gallery/reading-machines/>. Acesso em:08 set. 2019.

IT came from beneath the sea (O monstro do mar revolto). Direção: Robert Gordon, Produção: Charles H. Schneer, USA, 1955, p\&b, 79 min., sonoro.

KIMBALL, Roger. G. C. Lichtenberg: a "spy on humanity". New Criterion, v. 20, n.9, 2002. Disponível em: <https://www.newcriterion.com/issues/2002/5/g-c-lichtenberg-a-ldquospy-onhumanityrdquo>. Acesso: 09 set. 2017.

LE VOYAGE dans la Lune (Viagem à Lua). Direção: Georges Méliès, Produção: Georges Méliès, França, 1902, colorido (colorido à mão), p\&b, 13 min., mudo.

MATERNO, Angela. Os radiodramas de Walter Benjamin. O percevejo: revista de teatro, crítica e estética, Rio de Janeiro, n. 6, p. 35-63, 1998.

MENDES, Murilo. Poesia completa e prosa. Volume único. Rio de Janeiro: Nova Aguilar, 1994. (Biblioteca Luso-brasileira. Série Brasileira) 
METROPOLIS. Direção: Fritz Lang, Produção: Erich Pommer, Alemanha, 1927, p\&b, 153 min., mudo.

MINK, Janis. Marcel Duchamp 1887-1968: a arte como contra-arte. Köln: Taschen, 1996.

MURICY, Katia. Alegorias da dialética: imagem e pensamento em Walter Benjamin. Rio de Janeiro: Relume Dumará, 1998.

RAFFAINI, Patrícia Tavares. Museu contemporâneo e os gabinetes de curiosidades. Revista do museu de arqueologia e etnologia, São Paulo, v. 3, p.159-164, 1993.

ROBEY, Tim.Kubrick by candlelight: how Barry Lyndon became a gorgeous, period-perfect masterpiece.The Telegraph. Film. July 2016. Disponível em:

<https://www.telegraph.co.uk/films/2016/07/27/kubrick-by-candlelight-how-barry-lyndon-became-agorgeous-period/>.. Acesso em: 09 set. 2019.

SPECTROPHONE and Parlamonium (Walter Benjamin, 1933). Museum of imaginary musical instruments. [2000]. Disponível em: <http://imaginaryinstruments.org/spetrophone-andparlamonium/>. Acesso em: 31 mar. 2017.

STEINER, George. A viagem crepuscular de Walter Benjamin. Folha de S. Paulo. +mais! São Paulo, 04 fev. 2001. Disponível em: <http://www1.folha.uol.com.br/fsp/mais/fs0402200103.htm〉. Acesso em: 12 set. 2017.

THE ADVENTURES of Baron Munchausen (As aventuras do Barão de Munchausen). Direção: Terry Gilliam, Produção: Thomas Schühly, GBR/ Itália, 1988, colorido, 126 min., sonoro.

THE NIGHTMARE before christmas (O estranho mundo de Jack). Direção: Henry Selick, Produção: Tim Burton, Denise Di Novi, Don Hahn, USA, 1993, colorido, 76 min., sonoro.

THE 7TH voyage of Sinbad (Simbad e a princesa). Direção: Nathan Juran, Produção: Charles H. Schneer, GBR / EUA, 1958, colorido, 88 min., sonoro.

ZITATE über Traum von Georg Christoph Lichtenberg deutscher Physiker und Schriftsteller (1742 1799): 3 Zitate, Sprüche \& Aphorismen. Gutzitiert. Disponível em:

$<$ https://www.gutzitiert.de/zitat_autor_georg_christoph_lichtenberg_thema_traum_839.html >.Acesso em: 11 set. 2017. 


\section{ANEXO A - LICHTENBERG - ficha técnica}

DIREÇÃO

Lau Caminha Aguiar

DIREÇÃO DE FOTOGRAFIA

Marco Aurélio Ribeiro

Eduardo Xavier

EDIÇÃO

Lau Caminha Aguiar

ASSISTENTES DE EDIÇÃO

Mariana Borges

Daniel Ferreira

Bruno Lobo

Ítalo Gutemberg

Deise Oliveira

DESENHO DE PRODUÇÃO

Lau Caminha Aguiar

ANIMADORES STOP MOTION

Arnaldo Fabbri Cunha

Marcus Flávio dos Santos

DESENHO DE ÁUDIO E CAPTAÇÃO DAS VOZES DOS ATORES

Alexandre Martins - REC Studios

\section{ATORES}

Luciano Luppi: Lichtenberg

Dirceu Valadares: Narrador

Alex Zanon: Labu

Adilson Maghá: Sofanti

Ronaldo Jannotti: Peka

Lau Caminha Aguiar: Quikko

Ricardo Righi: David Garrick

Ricardo Righi: Imortal

Pedro Henrique Vieira: Mordomo Real.

Maria Clara de Souza: Dorothea

Rogério M. A. Aguiar: Eberhard

Kadu Barcelos: Primeiro cidadão

Leonardo Horta: Segundo cidadão

Fábio Schmidt: Terceiro cidadão

Laly Cataguases: Pastor

ARGUMENTO ORIGINAL

Walter Benjamin

TRADUÇÃO DO ORIGINAL ALEMÃO

Daniel M. C. Rosa

REVISÃO DO TEXTO

Professor doutor Georg Wink 
MODELAGEM DOS ROSTOS DOS PERSONAGENS

Paulo Emílio Luz

ESQUELETOS PARA STOP MOTION

Thiago Guimarães

Willian Salvador (in memoriam)

FIGURINOS

Guiomar da Silva

Original recebido em: 04 de setembro de 2018

Aceito para publicação em: 22 de maio de 2019

José Wenceslau Caminha Aguiar Junior

Doutor em Linguagens Visuais pela Escola de Belas Artes/UFRJ. Mestre em Artes Visuais e Bacharel em Artes Plásticas pela Escola de Belas Artes/UFMG. Professor na Escola Guignard/UEMG. Artista multimídia e cineasta.

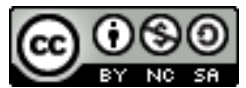

Esta obra está licenciado com uma Licença

Creative Commons Atribuição-NãoComercial-CompartilhaIgual 4.0 Internacional 